\title{
Improved growth of bifidobacteria by cocultivation with Lactococcus lactis subspecies lactis
}

\author{
S. Yonezawa, ${ }^{11}$ J. Z. Xiao, ${ }^{*}$ T. Odamaki, ${ }^{*}$ T. Ishida,† K. Miyaji,† A. Yamada, ${ }^{*}$ T. Yaeshima, ${ }^{*}$ and K. Iwatsuki ${ }^{*}$ \\ ${ }^{*}$ Food Science \& Technology Institute and \\ †Food Research \& Development Institute, Morinaga Milk Industry Co. Ltd., Zama, Kanagawa 228-8583, Japan
}

\begin{abstract}
Cultivation of bifidobacteria in milk is a difficult and industrially valuable task. In this paper, we report the finding of a novel technique to improve the growth of bifidobacteria in dairy products and the results of mechanism studies. The growth of bifidobacteria in skim milk medium was found to be stimulated upon cocultivation with certain strains of Lactococcus lactis ssp. lactis. Bifidobacterium growth-stimulating (BGS) activity was observed on a wide range of bifidobacterial species. Bifidobacterium growth-stimulating activity was associated with the ability to grow in skim milk medium and the presence of a cell wall-anchored proteinase (PrtP) in Lc. lactis ssp. lactis. Studies on one strain, Lc. lactis ssp. lactis MCC857, showed that crude PrtP extracts and casein hydrolysates exhibited BGS activity. The casein hydrolysate BGS activity was found in the low molecular weight fraction by HPLC separation. A combination of $2 \mathrm{AA}$, Met and Leu, was found to account for a large portion of the casein hydrolysate BGS activity. In conclusion, this cocultivation system is highly efficient and industrially applicable for the production of fermented milk with high cell counts of bifidobacteria.
\end{abstract}

Key words: Bifidobacterium, Lactococcus lactis, growth, amino acid

\section{INTRODUCTION}

Bifidobacteria are acknowledged to be major components of the intestinal microflora of humans and animals and are frequently associated with healthpromoting effects (Turroni et al., 2009). The beneficial effects of these bacteria on the intestinal flora, as well as other physiological effects, are well documented and have been recently reviewed (Leahy et al., 2005; Picard et al., 2005). For this reason, there has been increas-

Received September 8, 2009.

Accepted January 20, 2010.

${ }^{1}$ Corresponding author: s-yonezawa@morinagamilk.co.jp ing interest in creating food products containing these bacteria as dietary probiotics.

To provide health benefits, fermented products should contain an adequate level of live probiotic bacteria at the use-by date. Assuming a daily fermented milk consumption of $100 \mathrm{~g}$, the minimal level of probiotic bacteria suggested is $10^{6} \mathrm{cfu} / \mathrm{g}$ based on the daily efficient dose $\left(10^{8} \mathrm{cfu}\right)$ for these products (Vanderhoof and Young, 1998). However, the cultivation of bifidobacteria in cow milk is a difficult task compared with the cultivation of conventional starters because cow milk is an artificial medium for the growth of these nutritionally fastidious microorganisms. Low concentrations or inaccessible forms of essential nutrients in cow milk may be important factors that impair the ability of bifidobacteria to grow in cow milk. As an example, several AA (e.g., Arg, Ile, Leu, Trp, Tyr, Cys, and Val), which are either stimulatory or essential for growth of bifidobacteria and lactobacilli, are generally present in insufficient amounts at states as either free AA or low molecular mass peptides (Thomas and Pritchard, 1987; Poch and Bezkorovainy, 1988; Poch and Bezkorovainy, 1991). Therefore, cow milk-based media are usually supplemented with specific protein hydrolysates and yeast extracts to enhance the growth of bifidobacteria (Poch and Bezkorovainy, 1988; Gomes et al., 1998).

Bifidobacteria generally produce acetic acid and lactic acid from lactose, but are unable to generate sufficient acids for the manufacture of fermented milk products with the appropriate aroma and flavor. Therefore, they are normally incorporated as live cultures into fermented dairy products that can serve as carrier foods, such as yogurt, fermented by ordinary lactic acid bacterial starters, such as Streptococcus thermophilus and Lactobacillus delbrueckii ssp. bulgaricus (Samona and Robinson, 1994). Some lactic acid bacteria strains, e.g., Lactococcus lactis, Lactobacillus helveticus, Lb. delbrueckii ssp. bulgaricus, and, in rare case, Str. thermophilus are known to possess cell wall-anchored proteinases. Some strains of Lc. lactis are known to possess a cell wall-anchored proteinase (PrtP) that functions in hydrolyzing milk proteins and supplying nitrogen sources such as oligopeptides or free AA for bacterial growth 
in nonsupplemented skim milk (Juillard et al., 1995b). Therefore, we were motivated to determine whether such Lc. lactis strains would be capable of supplying nitrogen nutrients to bifidobacteria when they are cocultivated. In this report, we present results of improved growth of bifidobacteria by cocultivation with strains of Lc. lactis ssp. lactis together with data on mechanistic studies of Bifidobacterium growth-stimulating (BGS) activity of the strain MCC 857.

\section{MATERIALS AND METHODS}

\section{Bacterial Strains and Growth Conditions}

Lactococcus lactis ssp. lactis ATCC19435 and all bifidobacterial type strains (Bifidobacterium longum ssp. infantis ATCC15697, Bifidobacterium breve ATCC15700, Bifidobacterium longum ssp. longum ATCC15707, Bifidobacterium adolescentis ATCC15703, and Bifidobacterium pseudocatenulatum ATCC27919) were purchased from the American Type Culture Collection (Rockville, $\mathrm{MD}$ ). Other strains of Lc. lactis were stock culture in the Morinaga Culture Collection (MCC; Morinaga Milk Industry Co. Ltd., Zama, Japan), which were obtained from dairy products. Bifidobacterium longum BB536 (=ATCC BAA-999) is a probiotic strain in the MCC stock that was obtained from feces of a healthy infant. Seed cultures of Lc. lactis ssp. lactis strains were grown at $30^{\circ} \mathrm{C}$ for $16 \mathrm{~h}$ in $10 \%$ (wt/wt) reconstituted skim milk (Morinaga Milk Industry Co. Ltd.) containing $0.2 \%$ (wt/wt) yeast extract (Becton and Dickinson Laboratories, Detroit, MI). Seed cultures of bifidobacterial strains were prepared in reinforced clostridial medium (Oxoid Ltd., Hampshire, UK) at $37^{\circ} \mathrm{C}$ for $16 \mathrm{~h}$ in glass test tubes. However, seed culture of B. longum ssp. longum BB536, a probiotic strain widely applied in fermented milk production, was generally prepared, as industrially, by culturing at $37^{\circ} \mathrm{C}$ for $4 \mathrm{~h}$ in $11 \%$ (wt/ wt) reconstituted skim milk containing $0.2 \%$ (wt/wt) yeast extract in glass test tubes. Bacteria were enumerated by plating appropriate dilutions of each culture on transgalactosylated oligosaccharides propionate agar (Eiken Chemical Co. Ltd., Tokyo, Japan) and M17 (Oxoid Ltd.) for Bifidobacterium spp. and Lc. lactis, respectively.

\section{Growth of Lc. lactis in Milk Medium}

One percent of seed cultures from each strain of $L c$. lactis ssp. lactis were added to $3 \mathrm{~mL}$ of heat-pretreated $\left(95^{\circ} \mathrm{C}\right.$ for $\left.30 \mathrm{~min}\right) 10 \%$ skim milk medium in glass test tubes and incubated at $30^{\circ} \mathrm{C}$ for $16 \mathrm{~h}$. After cultivation, medium $\mathrm{pH}$ was checked using a $\mathrm{pH}$ meter (Horiba Ltd., Kyoto, Japan) and bacteria were enumerated as described above.

\section{Cocultivation of Lc. lactis with Bifidobacteria}

First, $1 \%$ of the B. longum BB536 seed culture prepared in milk medium and $1 \%$ of seed cultures of each strain of Lc. lactis ssp. lactis were inoculated to $3 \mathrm{~mL}$ of heat-pretreated $\left(95^{\circ} \mathrm{C}\right.$ for $\left.30 \mathrm{~min}\right) 10 \%$ skim milk medium in glass test tubes and incubated at $37^{\circ} \mathrm{C}$ for 16 $\mathrm{h}$. The inoculated cell numbers were approximately $2 \times$ $10^{7} \mathrm{cfu} / \mathrm{mL}$ for both bifidobacteria and Lc. lactis.

Then, the effect of Lc. lactis on the growth of other bifidobacterial species was examined using the strain Lc. lactis ssp. lactis MCC857. To avoid inclusion of antioxidant reagent existing in reinforced clostridial medium, inocula of bifidobacteria were prepared in de Man, Rogosa, and Sharpe broth (Becton and Dickinson Laboratories) for $16 \mathrm{~h}$ at $37^{\circ} \mathrm{C}$. Microorganisms were collected by centrifugation and resuspended in sterile saline to a concentration of approximately $5 \times 10^{8} \mathrm{cfu} /$ $\mathrm{mL}$. One percent of the bifidobacterial cell suspension and $0.1 \%$ of starter cultures of Lc. lactis ssp. lactis MCC857 were inoculated to $3 \mathrm{~mL}$ of heat-pretreated $\left(95^{\circ} \mathrm{C}\right.$ for $\left.30 \mathrm{~min}\right) 10 \%$ skim milk medium in glass test tubes and incubated at $37^{\circ} \mathrm{C}$ for $16 \mathrm{~h}$. After cultivation, medium $\mathrm{pH}$ was checked and bacteria of Bifidobacterium and Lc. lactis were enumerated as described above.

\section{Assay of BGS Activity}

Bifidobacterium growth-stimulating activity was assayed using the strain $B$. longum BB536. One percent of the B. longum BB536 seed culture was inoculated to heat-pretreated $\left(95^{\circ} \mathrm{C}\right.$ for $\left.30 \mathrm{~min}\right) 10 \%$ reconstituted skim milk. After adding the test samples (e.g., crude PrtP solution, HPLC fractions, or AA added at appropriate ratio as described below), the inoculated medium was incubated under anaerobic condition (AnaeroPackAnaero, Mitsubishi Gas Chemical Co. Ltd., Tokyo, Japan) at $37^{\circ} \mathrm{C}$ for $16 \mathrm{~h}$. Incubation without sample supplementation was used as control. Bifidobacterium growth-stimulating activity was expressed as a stimulation index calculated by the ratio of cell numbers of bifidobacteria, determined as described above for each sample, against control.

\section{prtP Gene Detection and Enzyme Activity Assay}

Extraction of DNA from lactococcal strains was performed using the DNeasy Blood \& Tissue Kit according to the manufacturer's instructions (Qiagen Sciences, Gaithersburg, MD). Polymerase chain reaction detection of the prtP gene was performed as described previously (Broadbent et al., 2006). Briefly, the PCR mixture was performed using TaKaRa Ex Taq (Takara Bio Inc., Shiga, Japan) according to the manufacturer's 
instructions. Two sets of PCR primer pairs were used for the specific detection of prtP alleles encoding group b [primers GB $_{\mathrm{f}}($ GCAAATACGGTGACGGCTGCGA) and GB2 $2_{r}$ (TGAGCTTATAATAGGTCTTCTTCC)] and group $\mathrm{h}$ [primers $\mathrm{GH}_{\mathrm{f}}$ (CAAATACGGTGACGGCTGCTAA) and $\mathrm{GH}_{\mathrm{r}}$ (TAGCATTATAATAGGTCTTCGTCA)]. Amplification of prtP fragments was achieved using a 2 -min hot start at $94^{\circ} \mathrm{C}$, followed by 25 cycles of denaturation at $94^{\circ} \mathrm{C}$ for $10 \mathrm{~s}$, primer annealing at $58^{\circ} \mathrm{C}$ for $30 \mathrm{~s}$, and extension at $72^{\circ} \mathrm{C}$ for $1 \mathrm{~min}$. The reaction was finished with $5 \mathrm{~min}$ incubation at $72^{\circ} \mathrm{C}$ and then chilled to $4^{\circ} \mathrm{C}$. Polymerase chain reaction products, which were expected to size PCR fragment of $2.7 \mathrm{~kb}$, were resolved using $1.0 \%$ agarose gel electrophoresis.

Release of PrtP from Lc. lactis ssp. lactis MCC857 was performed as described previously (Laan and Konings, 1989; Exterkate and Alting, 1999). The bacteria were grown to $\mathrm{pH} 5.0$ in a medium containing $10 \%$ reconstituted skim milk (pasteurized at $63^{\circ} \mathrm{C}$ for $30 \mathrm{~min}$ ) and $70 \mathrm{mM} \beta$-glycerophosphate (sterilized at $121^{\circ} \mathrm{C}$ for $15 \mathrm{~min})$. The cells were harvested by centrifugation $\left(5,000 \times g, 10 \mathrm{~min}, 4^{\circ} \mathrm{C}\right)$ and washed twice with $30 \mathrm{mM}$ sodium 2-( $N$-morpholine)ethanesulfonic acid (MES)$\mathrm{NaOH}$ (pH 6.5; Sigma-Aldrich Co., St. Louis, MO) containing $10 \mathrm{mM} \mathrm{CaCl}$. The cells were suspended in $1 / 20$ culture volume of $30 \mathrm{~m} M$ MES-NaOH containing $10 \mathrm{~m} M$ EDTA-2Na for $10 \mathrm{~min}$ at $30^{\circ} \mathrm{C}$ to release the enzyme from the cell walls and centrifuged $(8,500 \times g$. $10 \mathrm{~min}, 4^{\circ} \mathrm{C}$ ), and the supernatant was collected as a crude PrtP extract. The extract was dialyzed in $30 \mathrm{mM}$ MES-NaOH containing $10 \mathrm{mM} \mathrm{CaCl}{ }_{2}$ at $4^{\circ} \mathrm{C}$ overnight. The crude PrtP extract was subjected to BGS assay as described above in $10 \%$ concentration. Proteinase activity was assayed with fluorescamine-labeled $\beta-\mathrm{CN}$ [0.1\% (wt/vol) $\beta-C N$; Sigma-Aldrich Co.] as substrate in $30 \mathrm{~m} M$ MES-NaOH (pH 6.5), as described previously (Twining, 1984). Standard assays were performed at $30^{\circ} \mathrm{C}$ for $60 \mathrm{~min}$. For inhibition of PrtP activity, a serine proteinase inhibitor, phenylmethanesulfonylfluoride (Sigma-Aldrich Co.), was added to the crude PrtP extract at a final concentration of $1 \mathrm{~m} M$ and incubated at room temperature for $20 \mathrm{~min}$ (Laan and Konings, 1989). The mixture was then assayed for BGS activity as described above.

\section{Identification of BGS Components from PrtP-CN Hydrolysis}

Cells of Lc. lactis ssp. lactis MCC857, prepared as described in isolation of PrtP, were suspended in a $1 / 20$ culture volume of $30 \mathrm{~m} M$ MES-NaOH containing $10 \mathrm{mM} \mathrm{CaCl}$. The cell suspension was mixed in a 1:9 ratio with $1 \%$ prepasteurized (at $85^{\circ} \mathrm{C}$ for $10 \mathrm{~min}$ ) $\mathrm{CN}$
(pH 6.5; Merck Inc., Whitehouse Station, NJ) and incubated at $30^{\circ} \mathrm{C}$ for $24 \mathrm{~h}$. After incubation, the mixture was denatured by boiling for $10 \mathrm{~min}$ and adjusted to $\mathrm{pH}$ 4.6 by $\mathrm{HCl}$. The mixture was centrifuged $(8,500 \times g, 10$ min, room temperature) to remove insoluble constituents. One liter of the supernatant was concentrated to $1 / 100$ volume by freeze-drying and passed through an Amicon Ultra 3000 Da molecular filter (peptides or proteins; Millipore Co., Billerica, MA), and the permeate fraction was collected as whole hydrolysate (finally $10 \mathrm{~mL}$ ). The hydrolysate was subjected to BGS assay as described above in $1 \%$ concentration.

The CN hydrolysate was separated by HPLC using a $\mathrm{C}_{18}$ reversed-phase column $(10 \mathrm{~mm} \times 200 \mathrm{~mm}, 5 \mu \mathrm{m}$, $100 \AA$ A Shiseido Co. Ltd., Tokyo, Japan) with the following mobile phases: eluent A, $0.1 \%$ trifluoroacetic acid in Milli-Q water (Millipore Co.); eluent B, $0.1 \%$ trifluoroacetic acid in $80 \%$ acetonitrile (flow-rate: 4 $\mathrm{mL} / \mathrm{min}$; gradient: $0-25 \%$ acetonitrile in 10-50 min, $25-50 \%$ in $50-60 \mathrm{~min}$, and $50-80 \%$ in $60-63 \mathrm{~min})$. A total of 40 fractions were collected and vacuum-dried. Each fraction was dissolved in sterile distilled water at $1 / 40$ volume of original hydrolysate and subjected to BGS assay as described above in $0.025 \%$ concentration.

Molecular mass was measured using TSQ Quantum Discovery Max (Thermo Fisher Scientific Inc., Waltham, MA). The concentration of AA was determined by using precolumn derivatization with dansyl chloride (SigmaAldrich Co.). The samples were hydrolyzed with $6.0 \mathrm{~N}$ $\mathrm{HCl}$ at $150^{\circ} \mathrm{C}$ for $2 \mathrm{~h}$.

\section{Statistical Analysis}

All experiments were repeated in triplicate for determining standard deviation. Data were expressed as mean \pm standard deviation. Data were considered statically significant when $P$-values were $<0.05$, as determined by Student's $t$-test for comparisons of 2 groups or nonrepeated measures ANOVA followed by Bonferroni test for multiple comparisons with controls.

\section{RESULTS}

\section{Stimulation of Bifidobacterial Growth in Cocultivation with Lc. lactis}

Nineteen strains of Lc. lactis ssp. lactis were tested for BGS activity in cocultivation with B. longum BB536. Bifidobacterium longum BB536 growth was stimulated with 7 strains of Lc. lactis ssp. lactis (MCC852, MCC857, MCC858, MCC859, MCC865, MCC866, and MCC869), the medium $\mathrm{pH}$ values were lower than or near 4.5 , and the bifidobacterial counts were approxi- 
Table 1. Effect of Lactococcus lactis ssp. lactis cocultivation on bifidobacterial growth, Lactococcus lactis ssp. lactis fermentation of skim milk, and PCR detection of prtP genes in Lactococcus lactis ssp. lactis ${ }^{1}$

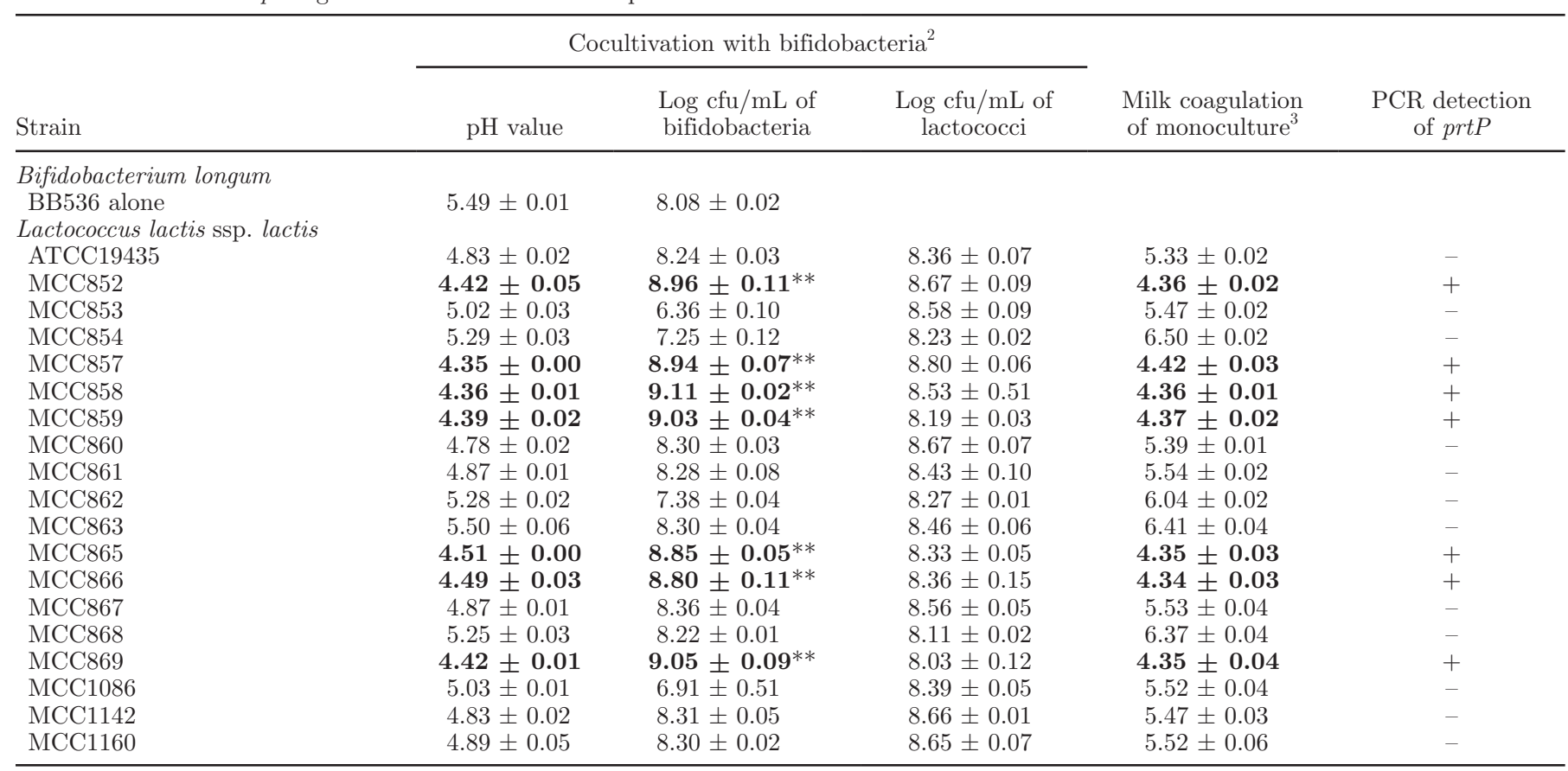

${ }^{1}$ Bold values indicate $\mathrm{pH}<4.6$.

${ }^{2}$ Bifidobacterium longum BB536 cultivated in skim milk alone or with each strain of Lactococcus lactis ssp. lactis at $37^{\circ} \mathrm{C}$ for $16 \mathrm{~h}$.

${ }^{3}$ Each strain of Lactococcus lactis ssp. lactis cultivated in skim milk at $30^{\circ} \mathrm{C}$ for $16 \mathrm{~h}$.

** $P<0.01 ;$ significantly higher compared with BB536 alone.

mately $10^{9} \mathrm{cfu} / \mathrm{mL}$, which was significantly higher $(5.3-$ to 11-fold) compared with B. longum BB536 cultivated in monoculture (Table 1).

The BGS activity of MCC857, one of the most active in acid production and most favorable strains for industrial applications, was further assayed for type strains of other bifidobacterial species (Table 2). Type strains of B. adolescentis ATCC15703 and B. pseudocatenulatum ATCC27919 failed to grow in skim milk medium, with cell numbers decreasing from the inoculated numbers. However, growth of each type strain of bifidobacteria was stimulated in cocultivation of Lc. lactis ssp. lactis MCC857, with bifidobacterial cell numbers increasing 143.4-, 93.2-, 65.4-, 1.6-, 8.4-, and 44.1-fold from the inoculated cell numbers and 10.9-, 7.7-, 13.4-, 29.7-, 2,020.7-, and 11.1-fold compared with monoculture of type strains of $B$. longum ssp. infantis ATCC15697, $B$. breve ATCC15700, B. longum ssp. longum ATCC15707, B. adolescentis ATCC15703, B. pseudocatenulatum ATCC27919, and B. longum BB536, respectively.

\section{Detection of prtP Genes from Lc. lactis}

The BGS-active strains of Lc. lactis were found to be able to coagulate skim milk medium with $\mathrm{pH}$ of $<4.5$ (Table 1). The cell numbers in the skim milk culture with these bacteria were around $10^{9} \mathrm{cfu} / \mathrm{mL}$, which were higher compared with those of BGS-inactive strains (data not shown). In coincidence with the ability to grow in skim milk, these strains were found to possess the prtP gene as detected by PCR (Table 1).

\section{Determination of BGS Activity in Crude PrtP Extracts from Lc. lactis ssp. lactis MCC857 and Identification of BGS-Active Components in Lc. lactis CN Hydrolysates}

Proteinase activity was observed in crude PrtP extracts from Lc. lactis ssp. lactis MCC857 (Figure 1). Additionally, supplementation of crude PrtP extracts enhanced BGS activity. The addition of the serine proteinase inhibitor phenylmethanesulfonylfluoride and heat treatment blocked proteinase and BGS activity (Figure 1).

Supernatants of skim milk cultures of Lc. lactis were found to be negative for BGS activity (data not shown), but supernatants of milk CN incubated with Lc. lactis, without a supplemental carbohydrate source, were found to be BGS-active (Figure 2). Bifidobacterium growth-stimulating activity was present in the supernatants and the permeate fraction (molecular weight $<3,000 \mathrm{Da}$ ) of ultrafiltration (Figure 2). Separa- 


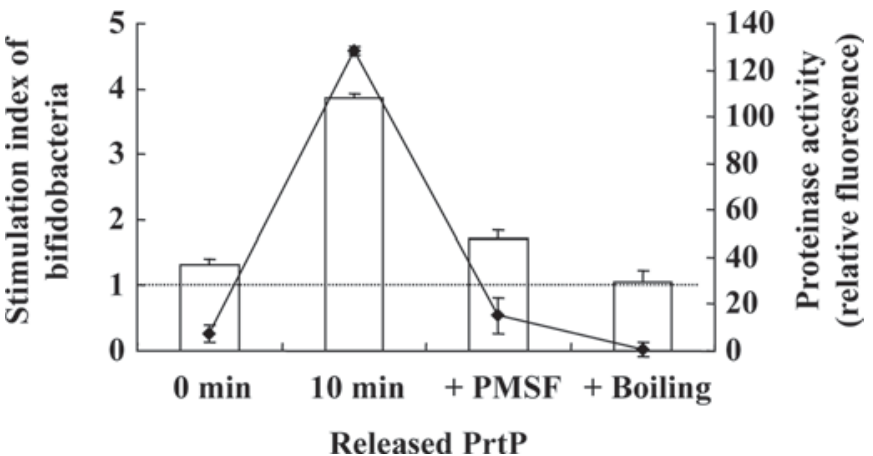

Figure 1. Bifidobacterium growth-stimulating activity on Bifidobacterium longum BB536, and proteinase activity of released PrtP (a cell wall-anchored proteinase) from Lactococcus lactis ssp. lactis MCC857. The solid line indicates the proteinase activity measured by the fluorescein isothiocyanate-CN hydrolysis method. Bars show the stimulation index of BB536 in each PrtP sample: 0 min $=$ supernatant of cell suspension before adding EDTA-2Na; $10 \mathrm{~min}=$ released crude PrtP fraction after incubation for 10 min with EDTA-2Na; + PMSF (phenylmethanesulfonylfluoride) $=$ released crude PrtP fraction further incubated with $1 \mathrm{~m} M$ serine proteinase inhibitor PMSF at room temperature for $30 \mathrm{~min}$; + boiling = released crude PrtP fraction further boiled for $10 \mathrm{~min}$. Bifidobacterium growth-stimulating activity is shown as a stimulation index calculated by the ratio of bifidobacterial cell numbers for each sample against control without sample supplementation. The dotted line indicates the level of control.

tion of the CN hydrolysate permeate by HPLC revealed the presence of several peaks presumed to comprise a variety of peptides and free AA (Figure 3A). Bifidobacterium growth-stimulating activity assays showed that individual fractions were not active (data not shown). However, combined fractions exhibited BGS activity, which was found to be mainly in the hydrophilic fractions (fraction 1-10; Figure 3B). A series of assays for the screening of active combinations among fractions 1 to 10 resulted in the identification of an active combination of fractions 2 and 10 . The mixture of fractions 2 and 10 accounted for approximately $60 \%$ of the BGS activity in the original permeates.

Table 3 shows the AA composition of fractions 2 and 10 , as well as the whole permeates of $\mathrm{CN}$ hydrolysate. Fraction 2 contained mainly Val and Met, whereas frac-

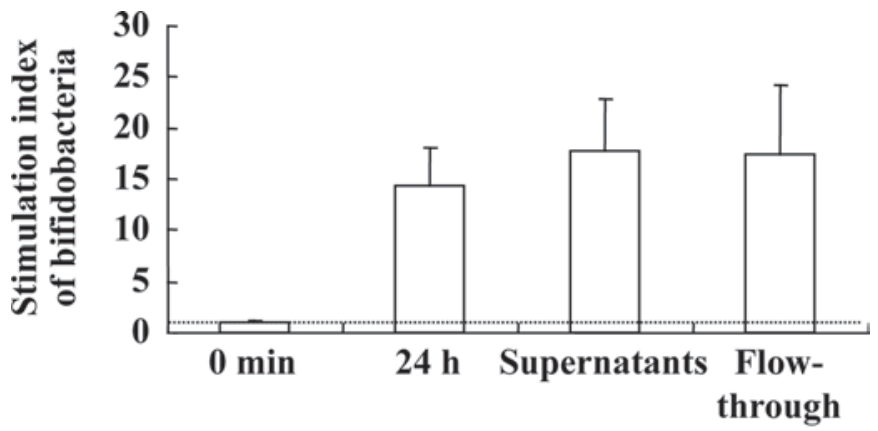

Casein hydrolysate

Figure 2. Bifidobacterium growth-stimulating activity of Lactococcus lactis ssp. lactis MCC857 CN hydrolysates on Bifidobacterium longum BB536: $0 \mathrm{~min}=\mathrm{CN}$ solution before hydrolysis; $24 \mathrm{~h}=$ hydrolyzed for $24 \mathrm{~h}$; supernatants = supernatant of hydrolysates after centrifugation; flow-through $=$ flow-through fraction of molecule filter with a cutoff value of 3,000 Da. Bifidobacterium growth-stimulating activity is shown as stimulation index calculated by the ratio of bifidobacterial cell numbers for each sample against control without sample supplementation. The dotted line indicates the level of control.

tion 10 contained mainly Leu and minor amounts of Gly and Pro. Based on MS analysis, the Gly and Pro in fraction 10 existed as a dipeptide, with the remainder as free AA.

To confirm the activity of the combination of fractions 2 and 10, BGS activity assays were performed by replacing the HPLC fractions with pure AA (Nacalai Tesque Inc., Kyoto, Japan; Figure 4). When fraction 10 was replaced with Leu, the BGS activity of the combinations did not change appreciably. When fraction 2 was replaced with Val, Met, or both, the majority of the activity was associated with the combination containing Met (data not shown). The mixture of pure Leu and Met had the same activity as the combination of fractions 2 and 10. No BGS activity was detected with other AA combinations or individual AA. These results indicated that Leu and Met were the main components associated with BGS activity in the combination of fractions 2 and 10.

Table 2. Bifidobacteria cells (log cfu/mL) in cocultivation with Lactococcus lactis ssp. lactis MCC857 or cultivated alone

\begin{tabular}{|c|c|c|c|}
\hline Strain & After inoculation & \multicolumn{2}{|c|}{ After incubation } \\
\hline Bifidobacterium breve ATCC15700 & $6.56 \pm 0.05$ & $7.64 \pm 0.06$ & $8.53 \pm 0.03^{* *}$ \\
\hline Bifidobacterium longum ATCC15707 & $6.87 \pm 0.09$ & $7.52 \pm 0.11$ & $8.65 \pm 0.12^{* *}$ \\
\hline Bifidobacterium adolescentis ATCC 15703 & $6.81 \pm 0.16$ & $5.55 \pm 0.36$ & $7.02 \pm 0.09^{* *}$ \\
\hline
\end{tabular}

** $P<0.01$; significant difference in bifidobacterial cell numbers of those cocultivated with Lc. lactis compared with those cultivated alone. 
A)

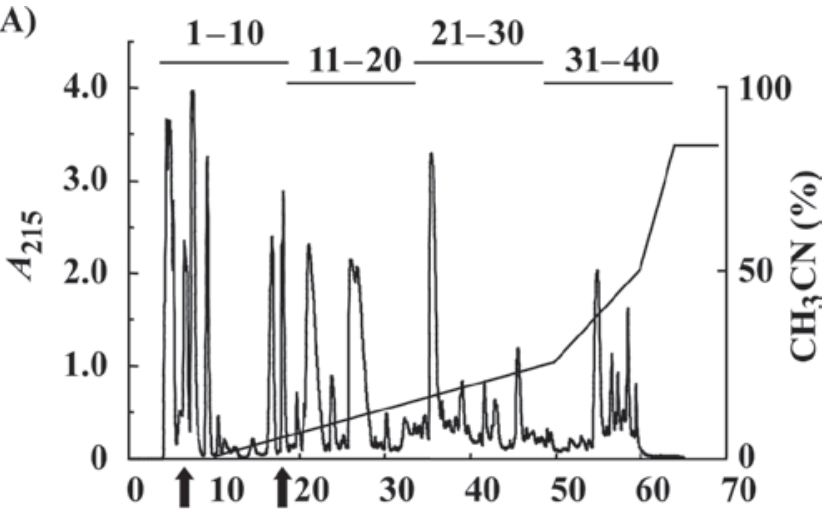

Fraction $2 \quad 10$

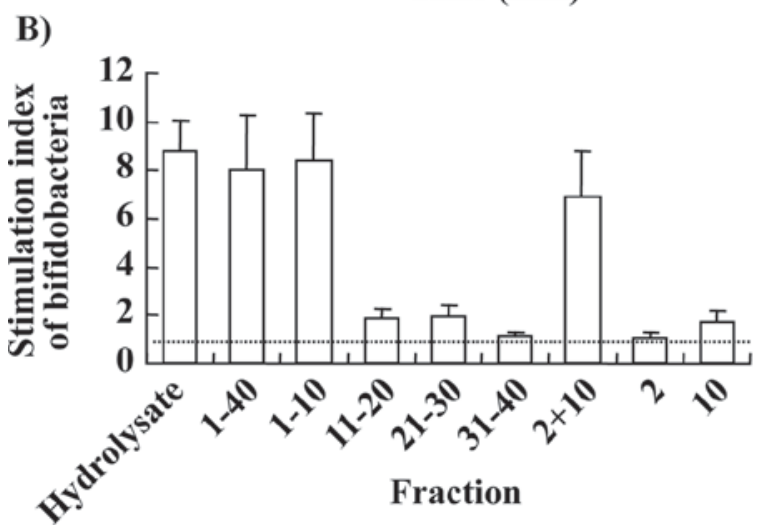

Figure 3. A) The HPLC profile of the Lactococcus lactis ssp. lactis MCC857 CN hydrolysate. B) Bifidobacterium growth-stimulating activity of each HPLC fraction on Bifidobacterium longum BB536. Bifidobacterium growth-stimulating activity is shown as stimulation index calculated by the ratio of bifidobacterial cell numbers for each sample against control without sample supplementation. The dotted line indicates the level of control.

\section{DISCUSSION}

In this study, we found that cocultivation with some Lc. lactis ssp. lactis strains stimulated the growth of bifidobacteria in skim milk medium. Bifidobacterium growth-stimulating activity was associated with the ability to grow in skim milk as well as the presence of a cell wall-anchored proteinase (PrtP) in strains of Lc. lactis ssp. lactis. Furthermore, BGS activity was observed in $\mathrm{CN}$ hydrolysates produced with the active strains, with Leu and Met identified as the main components that partly accounted for the BGS activity in the strain $L c$. lactis ssp. lactis MCC857 CN hydrolysate.

Several reports have demonstrated the poor growth of bifidobacteria in skim or whole milk, which has been attributed to a lack of essential vitamins (Desjardins et al., 1990) or a lack of essential AA (Roy et al., 1990; Gomes et al., 1998). Various biological materials have been tested for their growth-promoting activity (such as yeast extracts, bovine $\mathrm{CN}$ digests, human and bovine

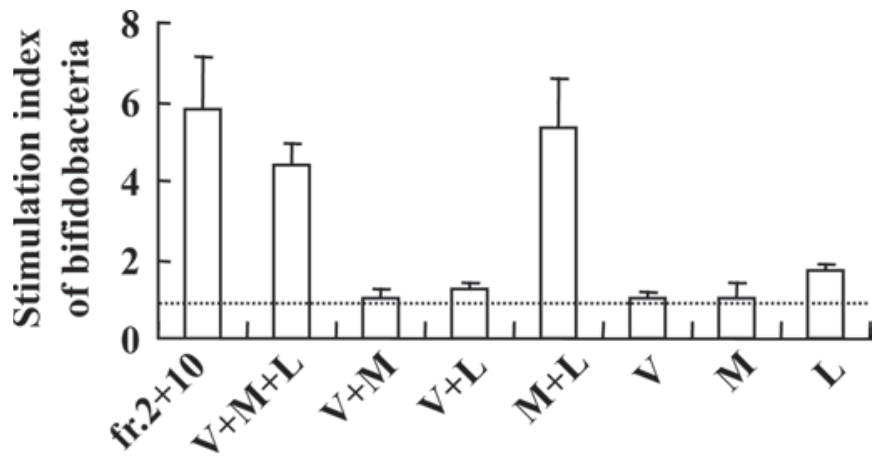

Fraction or AA

Figure 4. Bifidobacterium growth-stimulating (BGS) activity of HPLC fractions and AA on Bifidobacterium longum BB536. Pure Val $(\mathrm{V})$, Met $(\mathrm{M})$, or Leu (L) or mixtures of these were assayed for BGS activity at concentrations present in HPLC fractions 2 and 10 (final concentrations at 97,75 , and $107 \mu M$ for Val, Met, and Leu, respectively, or their mixtures). Bifidobacterium growth-stimulating activity is shown as a stimulation index calculated by the ratio of bifidobacterial cell numbers for each sample against control without sample supplementation. The broken line indicates the level of control.

milk whey, hog gastric mucin, and BSA digest) and were demonstrated to be effective for some bifidobacterial species, although the nature of these growth factors has not yet been well determined (Poch and Bezkorovainy, 1988; Kiviharju et al., 2005). Etoh et al. (2000) identified an active peptide for the growth of Bifidobacterium bifidum from natural rubber serum powder. Liepke et al. (2002) identified several bifidogenic peptides from pepsin-treated human milk. Gomes et al. (1998) reported that the growth and acid production of Bifidobacterium animalis ssp. lactis strain Bo, but not Lactobacillus

Table 3. Composition and concentration $(\mu M)$ of AA in whole casein hydrolysate and HPLC fractions subjected to assay for Bifidobacterium growth-stimulating activity

\begin{tabular}{|c|c|c|c|}
\hline \multirow[b]{2}{*}{ Item } & \multirow{2}{*}{$\begin{array}{l}\text { Whole casein } \\
\text { hydrolysate }\end{array}$} & \multicolumn{2}{|c|}{ HPLC fraction } \\
\hline & & Fraction 2 & Fraction 10 \\
\hline Asp & 93 & 1 & $\mathrm{ND}^{1}$ \\
\hline Glu & 429 & 3 & ND \\
\hline Ser & 64 & 1 & ND \\
\hline Thr & 37 & ND & ND \\
\hline Gly & 169 & 1 & 5 \\
\hline $\mathrm{Arg}$ & 49 & 1 & ND \\
\hline Ala & 137 & 1 & ND \\
\hline Pro & 557 & 5 & 3 \\
\hline Val & 311 & 97 & ND \\
\hline Met & 86 & 75 & ND \\
\hline Ile & 167 & ND & ND \\
\hline Leu & 297 & ND & 107 \\
\hline Phe & 145 & ND & ND \\
\hline Cys & 16 & ND & ND \\
\hline Lys & 210 & 1 & ND \\
\hline His & 49 & ND & ND \\
\hline Tyr & 45 & ND & ND \\
\hline
\end{tabular}

${ }^{1} \mathrm{ND}=$ not detected. 
acidophilus strain Ki, was promoted by proteinase- or neutrase-mediated hydrolysates. Cocultivation of $B$. animalis ssp. lactis Bo with Lb. acidophilus Ki led to enhanced rates of growth and acidification when compared with that of the individual cultures, suggesting some degree of symbiosis between the strains. They suggested that $L b$. acidophilus Ki could hydrolyze milk CN using a cell wall-anchored proteinase to produce more low molecular mass nitrogen (especially peptides) to further growth and, consequently, aid in the growth of and acidification by $B$. animalis ssp. lactis Bo. Stimulatory interactions involving nitrogen requirements have previously been observed between several bifidobacterial strains and proteolytic lactobacilli (Klaver et al., 1993). To our knowledge, however, evaluation of promoting effects were restricted to certain bifidobacterial strains in these studies, and determination of the mechanisms or identification of active components have not been conducted.

Lactococci have numerous nutritional requirements for growth, particularly nitrogen sources (Reiter and Oram, 1962; Law, 1978). The AA requirement appears to be strain dependent, but most Lc. lactis strains require Ile, Leu, His, Met, and Val for growth (Chopin, 1993). Some strains of Lc. lactis are known to harbor a cell wall-anchored proteinase, PrtP, which hydrolyzes milk proteins and supplies nitrogen sources, such as various peptides and AA, for bacterial growth in milk media (Savijoki et al., 2006). The proteolytic system also includes several peptidases and 2 peptide transport systems in addition to the cell envelope-located proteinase. The gene prtP is generally located on plasmids (Siezen et al., 2005). The in vitro action of purified proteinases on $\mathrm{CN}$ has been studied in great detail (Juillard et al., 1995a). Juillard et al. (1995b) demonstrated that oligopeptides are the main source of nitrogen for Lc. lactis during growth in milk. Therefore, it is thought that oligopeptide transport is very likely to be the next step in the proteolytic pathway and is followed by internal degradation of the peptides by a variety of peptidase. To our knowledge, there is no report on the influence of the Lc. lactis proteolytic system on the growth of bifidobacteria during cocultivation. Our results showed that cocultivation of bifidobacteria with some PrtP-harboring strains resulted in markedly increased bifidobacterial cell numbers compared with bifidobacteria cultivated in monoculture. However, the effect did not appear to be mutually beneficial because bacterial counts of Lc. lactis were not prompted during cocultivation with bifidobacteria compared with those monocultivated at $37^{\circ} \mathrm{C}$ (data not shown). In addition, in experiments with supplements of Leu and Met at various concentrations to the cocultivating system, only the bacterial counts of $B$. longum, but not $L c$. lactis, were stimulated (data not shown).

It was expected that some nutritional components were provided from Lc. lactis that aided bifidobacterial growth during cocultivation; however, no BGS activity was found in the supernatants of PrtP-positive $L c$. lactis cultured individually in milk (data not shown). These findings suggest that PrtP-positive Lc. lactis is highly efficient in using the hydrolysates from milk proteins and that the utilization of the active components is complete for bacteria grown in monoculture. It has been previously reported that the proteolytic system of Lc. lactis is negatively controlled by a rich nitrogen source (Guédon et al., 2001). However, it was found that proteinase extracts were active in promoting bifidobacterial growth. Unfortunately, the enzyme released from the cells is autoproteolytic (Laan and Konings, 1991) and loss of activity occurs during incubation. This phenomenon accounts for the relatively low BGS activity in the crude PrtP extract (Figure 1). Because preparation of milk protein hydrolysates with enzyme extracts was not practically efficient, our strategy was to treat milk proteins with Lc. lactis in a condition without sufficient carbohydrate source for the bacterial growth. Consequently, relatively strong BGS activities were observed in the $\mathrm{CN}$ hydrolysates, with the BGS activities found in the low molecular weight fractions $(<3,000 \mathrm{Da})$.

High pressure liquid chromatography fractionation showed that the hydrolysates comprised numerous hydrophilic or hydrophobic peptides and AA, but no single fraction was positive for BGS activity. However, we found that BGS activity was maintained in mixtures of certain fractions and have succeeded in identifying a combination of $2 \mathrm{AA}$, Leu and Met, that account for a large portion of the BGS activity in the CN hydrolysate produced by Lc. lactis ssp. lactis MCC857. It was unexpected that the active components were AA rather than oligopeptides because it has been demonstrated that peptides identified in milk CN hydrolyzed by $L c$. lactis are systematically longer than 4 residues, and no further extracellular degradation of the proteinasereleased peptides is expected. Juillard et al. (1995a) reported the peptides released from $\beta-\mathrm{CN}$ by the action of $\mathrm{P}_{\mathrm{I}}$-type proteinase (PrtP) from Lactococcus lactis ssp. cremoris Wg2 contained more than 100 different oligopeptides and, with the exception of Phe, significant release of AA or di- and tripeptides could not be observed. Three types of lactococcal PrtP $\left(\mathrm{P}_{\mathrm{I}}, \mathrm{P}_{\mathrm{III}}\right.$, and $\left.\mathrm{P}_{\mathrm{I} / \mathrm{III}}\right)$ with different cleaving sites have been identified for Lc. lactis (Exterkate et al., 1993; Flambard et al., 1998). Therefore, BGS active components may be strain-dependent. However, the possible involvement of 
oligopetides in stimulating bifidobacterial growth could not be excluded. In the case of another PrtP-positive strain, MCC866, no individual or combination of AA could be identified with BGS activity (data not shown). High pressure liquid chromatography fractionation of MCC866 CN hydrolysates gave a much larger proportion of hydrophobic fractions (with later retention time, mainly composed of oligopeptides) compared with that of MCC857. Bifidobacterium growth-stimulating activity was distributed broadly among numerous fractions (data not shown). Therefore, we suggest that peptidase released from autolysed or physically lysed cells of strain MCC857 probably function in processing oligopeptides to AA during CN hydrolysis. Differences in the type of PrtP, composition of peptidase, and bacterial autolysis properties may thus contribute to the outcomes of various hydrolysates. Further studies are needed to evaluate the mechanisms of PrtP hydrolysis for each strain of $L c$. lactis. Nevertheless, to our knowledge, this is the first report of the identification of bifidogenic components from milk protein hydrolysates produced by lactic acid bacteria, which may play a role in stimulating bifidobacterial growth under a cocultivation system in milk medium.

In conclusion, the stimulation of bifidobacterial growth upon cocultivation with $L c$. lactis is a highly efficient and industrially applicable technique for the production of fermented milk with high bifidobacterial cell numbers. This technique is currently being applied in the production of a variety of fermented milk products containing probiotic B. longum BB536 launched in the Japanese market. Furthermore, a markedly improved survivability of bifidobacteria was also observed in cocultivated fermented milk during refrigerated storage compared with those prepared with other normal yogurt starters such as Str. thermophilus and $L b$. delbrueckii ssp. bulgaricus. The results of the improved survivability together with mechanism studies will be reported in another paper.

\section{ACKNOWLEDGMENTS}

We express sincere thanks to H. Matsumoto and N. Kurisu (Morinaga Milk Industry Co. Ltd., Zama, Japan) for helpful technical assistance. We thank Y. Yamamoto (Kitazato University, Aomori, Japan) for critical reading of the manuscript and helpful comments.

\section{REFERENCES}

Broadbent, J. R., B. T. Rodriguez, P. Joseph, E. A. Smith, and J. L. Steele. 2006. Conversion of Lactococcus lactis cell envelope proteinase specificity by partial allele exchange. J. Appl. Microbiol. 100:1307-1317.
Chopin, A. 1993. Organization and regulation of genes for amino acid biosynthesis in lactic acid bacteria. FEMS Microbiol. Rev. $12: 21-37$.

Desjardins, M. L., D. Roy, and C. Toupin. 1990. Uncoupling of growth and acids production in Bifidobacterium ssp. J. Dairy Sci. 73:1478-1484.

Etoh, S., K. Asamura, A. Obu, K. Sonomoto, and A. Ishizaki. 2000. Purification and identification of a growth-stimulating peptide for Bifidobacterium bifidum from natural rubber serum powder. Biosci. Biotechnol. Biochem. 64:2083-2088.

Exterkate, F. A., and A. C. Alting. 1999. Role of calcium in activity and stability of the Lactococcus lactis cell envelope proteinase. Appl. Environ. Microbiol. 65:1390-1396.

Exterkate, F. A., A. C. Alting, and P. G. Bruinenberg. 1993. Diversity of cell envelope proteinase specificity among strains of Lactococcus lactis and relationship to change characteristics of the substratebinding region. Appl. Environ. Microbiol. 59:3640-3647.

Flambard, B., S. Helinck, J. Richard, and V. Juillard. 1998. The contribution of casein to the amino acid supply for Lactococcus lactis depends on the type of cell envelope proteinase. Appl. Environ. Microbiol. 64:1991-1996.

Gomes, A. M. P., F. X. Malcata, and F. A. M. Klaver. 1998. Growth enhancement of Bifidobacterium lactis $\mathrm{Bo}$ and Lactobacillus acidophilus Ki by milk hydrolysates. J. Dairy Sci. 81:2817-2825.

Guédon, E., P. Serror, S. D. Ehrlich, P. Renault, and C. Delorme. 2001 Pleiotropic transcriptional repressor CodY senses the intracellular pool of branched-chain amino acids in Lactococcus lactis. Mol. Microbiol. 40:1227-1239.

Juillard, V., H. Laan, E. R. S. Kunji, C. M. Jeronimus-Stratingh, A. P. Bruins, and W. N. Konings. 1995a. The extracellular $\mathrm{P}_{\mathrm{I}^{-}}$ type proteinase of Lactococcus lactis hydolyzes $\beta$-casein into more than one hundred different oligopeptides. J. Bacteriol. 177:34723478

Juillard, V., D. le Bars, E. R. S. Kunji, W. N. Konings, J. C. Gripon, and J. Richard. 1995b. Oligopeptides are the main source of nitrogen for Lactococcus lactis during growth in milk. Appl. Environ. Microbiol. 61:3024-3030.

Kiviharju, K., M. Leisola, and T. Eerikäinen. 2005. Optimization of a Bifidobacterium longum production process. J. Biotechnol. 117:299-308.

Klaver, F. A. M., F. Kingma, and A. H. Weerkamp. 1993. Growth and survival of bifidobacteria in milk. Neth. Milk Dairy J. 47:151164.

Laan, H., and W. N. Konings. 1989. Mechanism of proteinase release from Lactococcus lactis ssp. cremoris Wg2. Appl. Environ. Microbiol. 55:3101-3106.

Laan, H., and W. N. Konings. 1991. Autoproteolysis of the extracellular serine proteinase of Lactococcus lactis ssp. cremoris Wg2. Appl. Environ. Microbiol. 57:2586-2590.

Law, B. A. 1978. Peptide utilization by group N Streptococci. J. Gen. Microbiol. 105:113-118.

Leahy, S. C., D. G. Higgins, G. F. Fitzgerald, and D. van Sinderen 2005. Getting better with bifidobacteria. J. Appl. Microbiol. 98:1303-1315.

Liepke, C., K. Adermann, M. Raida, H. J. Mägert, W. G. Forssmann, and H. D. Zucht. 2002. Human milk peptides highly stimulating the growth of bifidobacteria. Eur. J. Biochem. 269:712-718.

Picard, C., J. Fioramonti, A. Francois, T. Robinson, F. Neant, and C. Matuchansky. 2005. Bifidobacteria as probiotic agentsPhysiological effects and clinical benefits. Aliment. Pharmacol. Ther. 22:495-512

Poch, M., and A. Bezkorovainy. 1988. Growth-enhancing supplements for various subspecies of the genus Bifidobacterium. J. Dairy Sci. $71: 3214-3221$

Poch, M., and A. Bezkorovainy. 1991. Bovine milk-casein trypsin digest is a growth enhancer for the genus Bifidobacterium. J. Agric. Food Chem. 39:73-77.

Reiter, B., and J. D. Oram. 1962. Nutritional studies on cheese starters. I. Vitamin and amino acid requirements of single strain starters. J. Dairy Res. 29:63-77. 
Roy, D., F. Dussault, and P. Ward. 1990. Growth requirements of Bifidobacterium strains in milk. Milchweissenschaft 45:500-502.

Samona, A., and R. K. Robinson. 1994. Effect of yogurt cultures on the survival of bifidobacteria in fermented milks. Int. J. Dairy Tech. 47:58-60.

Savijoki, K., H. Ingmer, and P. Varmanen. 2006. Proteolytic systems of lactic acid bacteria. Appl. Microbiol. Biotechnol. 71:394-406.

Siezen, R. J., B. Renckens, I. van Swam, S. Peters, R. van Kranenbeurg, M. Kleerebezem, and W. M. de Vos. 2005. Complete sequence of four plasmids of Lactococcus lactis ssp. cremoris SK11 reveal extensive adaptation to the daily environment. Appl. Environ. Microbiol. 71:8371-8382.
Thomas, T. D., and G. G. Pritchard. 1987. Proteolytic enzymes of dairy starter cultures. FEMS Microbiol. Rev. 46:245-268.

Turroni, F., D. van Sinderen, and M. Ventura. 2009. Bifidobacteria: From ecology to genomics. Front. Biosci. 14:4673-4684.

Twining, S. S. 1984. Fluorescein isothiocyanate-labeled casein assay for proteolytic enzymes. Anal. Biochem. 143:30-34.

Vanderhoof, J. A., and R. J. Young. 1998. Use of probiotics in childhood gastrointestinal disorders. J. Pediatr. Gastroenterol. Nutr. 27:323-332. 